OPEN ACCESS

Edited by:

Zhi Tian,

University of South Florida,

United States

Reviewed by:

Xingping Qin,

Renmin Hospital of Wuhan University,

China

Huan Cui,

Chinese Academy of Medical Sciences and Peking Union Medical

College, China

*Correspondence:

Christina M. Pabelick

pabelick.christina@mayo.edu

Specialty section:

This article was submitted to Integrative Physiology, a section of the journal

Frontiers in Physiology

Received: 11 January 2021

Accepted: 06 April 2021

Published: 27 April 2021

Citation:

Schiliro M, Vogel ER, Paolini L and Pabelick CM (2021) Cigarette Smoke

Exposure, Pediatric Lung Disease, and COVID-19.

Front. Physiol. 12:652198.

doi: 10.3389/fphys.2021.652198

\section{Cigarette Smoke Exposure, Pediatric Lung Disease, and COVID-19}

\author{
Marta Schiliro', Elizabeth R. Vogel' ${ }^{1}$, Lucia Paolini ${ }^{2}$ and Christina M. Pabelick ${ }^{1,3 *}$ \\ ${ }^{1}$ Department of Anesthesiology and Perioperative Medicine, Mayo Clinic, Rochester, MN, United States, \\ ${ }^{2}$ Department of Pediatric, San Gerardo Hospital, University of Milano-Bicocca, Fondazione MBBM, Monza, Italy, \\ ${ }^{3}$ Department of Physiology and Biomedical Engineering, Mayo Clinic, Rochester, MN, United States
}

The detrimental effects of tobacco exposure on children's health are well known. Nonetheless, the prevalence of secondhand or direct cigarette smoke exposure (CSE) in the pediatric population has not significantly decreased over time. On the contrary, the rapid incline in use of e-cigarettes among adolescents has evoked public health concerns since increasing cases of vaping-induced acute lung injury have highlighted the potential harm of these new "smoking" devices. Two pediatric populations are especially vulnerable to the detrimental effects of cigarette smoke. The first group is former premature infants whose risk is elevated both due to their prematurity as well as other risk factors such as oxygen and mechanical ventilation to which they are disproportionately exposed. The second group is children and adolescents with chronic respiratory diseases, in particular asthma and other wheezing disorders. Coronavirus disease 2019 (COVID-19) is a spectrum of diseases caused by infection with the severe acute respiratory syndrome coronavirus 2 (SARS-CoV-2) that has spread worldwide over the last year. Here, respiratory symptoms ranging from mild to acute respiratory distress syndrome (ARDS) are at the forefront of COVID-19 cases among adults, and cigarette smoking is associated with worse outcomes in this population, and cigarette smoking is associated with worse outcomes in this population. Interestingly, SARS-CoV-2 infection affects children differently in regard to infection susceptibility, disease manifestations, and complications. Although children carry and transmit the virus, the likelihood of symptomatic infection is low, and the rates of hospitalization and death are even lower when compared to the adult population. However, multisystem inflammatory syndrome is recognized as a serious consequence of SARS-CoV-2 infection in the pediatric population. In addition, recent data demonstrate specific clinical patterns in children infected with SARS-CoV-2 who develop multisystem inflammatory syndrome vs. severe COVID-19. In this review, we highlight the pulmonary effects of CSE in vulnerable pediatric populations in the context of the ongoing SARS-CoV-2 pandemic.

Keywords: cigarette smoke exposure, E-cigarette, vaping, lung, coronavirus disease 2019, pediatric, infection, inflammation 


\section{INTRODUCTION}

The detrimental effects of cigarette smoke exposure (CSE) on pediatric respiratory function have been well demonstrated (Jaakkola and Jaakkola, 1997; Weiss et al., 1999; Walker et al., 2003; Jackson et al., 2014; Liptzin et al., 2015). Although the number of cigarette smokers continues to decrease, new smoking devices (e-cigarettes) have spread among adolescents ${ }^{1}$ carrying with them the perception that they are "safer" than traditional tobacco products. This is especially concerning, since it is now well demonstrated that use of e-cigarettes is associated with subsequent use of traditional cigarettes, and vaping itself can cause significant lung injury, particularly among teenagers. ${ }^{2}$

Cigarette smoke exposure in children not only leads to wheezing, recurrent pulmonary and ear infections, and asthma, but it may also worsen pre-existing lung conditions (Weiss et al., 1999; Walker et al., 2003; Jackson et al., 2014). Here, former premature babies who suffer from chronic lung diseases following oxygen therapy and/or respiratory support are at increased risk. Similarly, children with asthma or chronic wheezing disorders often experience recurrent exacerbations and poor disease control when exposed to cigarette smoke.

The ongoing severe acute respiratory syndrome coronavirus 2 (SARS-CoV-2) pandemic has dramatically challenged healthcare systems and daily life worldwide and its ultimate impact on children affected by chronic lung conditions remains to be seen. At the beginning of the outbreak, few cases and less severe manifestations with low mortality rates were described in children (Chang et al., 2020), suggesting that adults, especially the elderly, were predominantly affected. Initially, children were largely considered a significant source of spread but not a population that would be critically impacted by infection. However, as the pandemic has unfolded, a shift toward the younger population has been reported in the United States (Boehmer et al., 2020) and Europe ${ }^{3}$, and children's unique infection susceptibility, disease manifestations, and health consequences are increasingly appreciated. ${ }^{4}$ In addition, societal restrictions imposed by the health crisis are challenging children's daily life, education, and socialization opportunities, thereby impacting the management of their chronic medical conditions. This is particularly true in lower-income settings. Currently, the long-term consequences of coronavirus disease 2019 (COVID-19) for children's health remain difficult to foresee.

With this review, we attempt to highlight the detrimental effects of CSE in the pediatric population with particular focus on vulnerable children, including premature babies and children with pre-existing lung conditions, and to discuss the potential interplay of SARS-CoV-2 infection in these settings.

\footnotetext{
${ }^{1}$ National Institute of Health (2018)

${ }^{2}$ Center for Disease Prevention and Control (2020)

${ }^{3}$ European Center for Disease Prevention and Control (2020)

${ }^{4}$ AAP (2020a)
}

\section{HOW BIG IS THE PROBLEM?}

\section{Cigarette Smoke Exposure in Children and Adolescents}

Cigarette smoke derives from burning tobacco products (e.g., cigarettes, cigars, and pipes) or smoke that has been exhaled by a person smoking. Secondhand smoke (SHS) exposure represents the typical source of CSE in children. In the US, more than 128 million nonsmokers are exposed to SHS at any age (Best et al., 2009). Children, however, have a higher risk of SHS exposure compared to the nonsmoking adult population because of their frequent exposure from household members (Gergen et al., 1998; Pirkle et al., 2006). The World Health Organization estimates that around 700 million children - almost half of the world's pediatric population - have significant exposure to SHS.

SHS exposure in children has a strong impact on their lifelong health and places a significant burden on the health care system. In the United States in 2010, exposure to SHS in children caused 101,570 visits to the emergency department with a total of 62.9 million dollars spent (Yao et al., 2019). Analysis from the Global Burden of Disease Study 2017 estimated that 63,822 pediatric $(<10$ years of age) deaths worldwide were ascribable to SHS exposure that year (GBD 2017 Risk Factor Collaborators, 2018).

Detrimental effects on respiratory function are common in children exposed to SHS. A systematic review and meta-analysis of 60 studies concluded that passive smoke exposure increases the risk of pediatric lower respiratory tract infections, with the risk becoming even greater in cases where both parents smoke (OR single smoking parent $1.22-95 \% \mathrm{Cl} 1.10-1.35$ - vs. OR both smoking parents $1.54-95 \% \mathrm{Cl} 1.40-1.69$; Jones et al., 2011). Not only does SHS exposure facilitate the onset of respiratory diseases and infections, but it may also exacerbate symptoms of pre-existing diseases such as asthma.

Airway diseases such as wheezing and asthma are the most common chronic respiratory disorders in the pediatric population and may have significant lifelong impact on children's health, even spanning into adulthood (von Mutius, 2001; Tai et al., 2014; Um-Bergstrom et al., 2019). According to the Center for Disease Control and Prevention (CDC) ${ }^{5}, 5.5$ million children under age 18 in the United States are currently affected by asthma, and 7.1 million suffer from respiratory allergies. CSE - both direct and secondhand - enhances the risk of developing asthma in infancy, childhood, and adolescence (Goksor et al., 2007; Burke et al., 2012; Thacher et al., 2014, 2018). A systematic review by Burke et al. (2012) showed that SHS exposure in children and young adults increases the incidence of asthma by $20 \%$. Moreover, SHS exposure is associated with more severe asthma symptoms (Akinbami et al., 2013; Hollenbach et al., 2017), increased risk of asthma exacerbations (Wang et al., 2015; Neophytou et al., 2018), and hospitalizations (Das, 2003; Wang et al., 2015).

Within the last decade, the introduction of e-cigarettes and vaping has evoked significant public health concerns,

${ }^{5} \mathrm{CDC}(2020 \mathrm{a})$ 
specifically in regard to youth. In fact, the number of adolescents who vape has constantly and significantly increased during the past few years (Centers for Disease Control and Prevention, 2013; Carroll Chapman and Wu, 2014; Miech et al., 2019). In 2019, over 5 million high schoolers (27.5\%) in the United States reported using e-cigs in the past 30 days, and, alarmingly, teenagers with asthma are even more likely than their non-asthmatic peers to try e-cigarettes (Choi and Bernat, 2016; Fedele et al., 2016; Larsen et al., 2016; Kim et al., 2017; Reid et al., 2018; Turner et al., 2018; Martinasek et al., 2019). Moreover, initial use of e-cigarettes during adolescence is strongly associated with subsequent traditional cigarette smoking, contributing to the increase of smoking in the adult population. Since March of 2019, outbreaks of e-cigarette and vaping product use-associated lung injury (EVALI) have been reported throughout the United States, in particular among adolescents $^{2}$ (Layden et al., 2020). EVALI is a clinical syndrome that comprises constitutional, respiratory, and gastrointestinal symptoms associated with inflammatory response and pulmonary infiltrates in patients who have recently used (within 90 days) e-cigarette products, and that is not ascribable to any other cause. EVALI is most associated with cannabinoid vaping and vitamin $\mathrm{E}$ acetate containing products ${ }^{2}$; however, the mechanisms responsible for vaping-induced lung injury are still under investigation. COVID-19 and EVALI have similar presenting symptoms. Therefore, a high level of suspicion for EVALI is still recommended during the COVID-19 pandemic since the possible overlap of clinical manifestations between COVID-19 and EVALI may lead to late EVALI diagnosis and treatment. This is highlighted by some recently reported clinical case series (Darmawan et al., 2020; Hassoun et al., 2020; Anderson et al., 2021).

\section{COVID-19 in Children}

The American Academy of Pediatrics together with The Children's Hospitals Association provides a "Weekly State Data Report" to trace COVID-19 cases in children in the United States. ${ }^{6}$ As of December 31,2020, children represent $12.4 \%$ of all the United States COVID-19 cases $(2,128,587 / 17,137,295)$. Of significance, pediatric COVID-19 cases have constantly increased over the last few months ( $17 \%$ increases in child cases over the last 2 weeks 12/17-12/31/2020). Hospitalizations and deaths are fortunately uncommon in United States children: between 0.2 and $3.4 \%$ of all pediatric COVID-19 cases resulted in hospitalization and 0.00 and $0.08 \%$ of all pediatric COVID-19 cases resulted in death. Similar trends are reported in Europe. ${ }^{7}$

Children of all ages are susceptible to SARS-CoV-2 infection, although most infected children are asymptomatic (Bellino et al., 2020; Davies et al., 2020; Dong et al., 2020; Parri et al., 2020). When symptomatic, children present with different clinical manifestations, laboratory, and radiological findings compared to adult patients (Verma and Amin, 2020; Xia et al., 2020). The incubation period is like adults, 2-14 days

\footnotetext{
${ }^{6}$ AAP (2020b)

${ }^{7}$ European Center for Disease Prevention and Control (2021)
}

with an average of 6 days. $^{8}$ Pediatric patients typically have a milder disease course overall. Significantly, children from low-income settings represent a high proportion of pediatric hospitalized patients; however, this seems not to be consistently related to worse outcome (Fernandes et al., 2021).

Presenting symptoms are mostly non-specific and self-limiting, which makes it difficult to distinguish COVID-19 from other common viral illnesses, possibly driving a lower testing rate in this population. Children may or may not have fever, and usually present either with cough or gastrointestinal symptoms in addition to more general symptoms such as rhinorrhea, sore throat, headache, and myalgia (Verma and Amin, 2020; Yoon et al., 2020; Fernandes et al., 2021). Of note, $40-50 \%$ of COVID-19 pediatric cases have a documented coinfection with other respiratory pathogens (Wu et al., 2020). Inflammatory markers are commonly not elevated in mild cases (Verma and Amin, 2020). Chest CT findings in pediatric COVID-19 cases with respiratory involvement showed unilateral or bilateral subpleural ground-glass opacities and consolidations with surrounding halo sign (Xia et al., 2020).

Since April of 2020, cases of children becoming severely ill after SARS-CoV-2 infection with features resembling Kawasaki disease have been increasingly reported ${ }^{9}$ (Riphagen et al., 2020; Verdoni et al., 2020). This severe clinical manifestation has been named multisystem inflammatory syndrome in children (MIS-C) associated with COVID-19. Initial CDC criteria ${ }^{10}$ for MIS-C included "(1) persistent fever $\geq 38.0^{\circ} \mathrm{C}$; (2) laboratory evidence of inflammation; (3) evidence of clinically severe disease requiring hospitalization; (4) multisystem $(\geq 2)$ organ involvement; (5) positive for current or recent SARS-CoV-2 infection; and (6) no alternative plausible diagnoses." It has become clear that MIS-C is a separate clinical and possibly pathological, entity from severe pediatric SARS-CoV-2 (Jiang et al., 2020). Interestingly, MIS-C cases lagged the COVID-19 case curve by 1 month and only one third of children diagnosed with MIS-C had RT-PCR positivity for SARS-CoV-2 depicting an active infection, while most of them were antibody positive (Jiang et al., 2020). A recent case series of 1,116 hospitalized pediatric patients from United States surveillance data has provided insights into the clinical characteristics and outcomes of children and adolescents with MIS-C compared with severe COVID-19 (Feldstein et al., 2021). Patients with MIS-C were more likely to be age 6-12 years, non-Hispanic black race, presenting severe cardiovascular or mucocutaneous involvement, and more severe inflammation. On the other hand, preliminary reports suggested that severe pediatric COVID-19 cases were more frequent in younger infants $(<1$ year of age; Gotzinger et al., 2020; Liu et al., 2020; Yang et al., 2020a), however, recent reports did not confirm this trend. COVID-19 severity in children seems to be associated with age $\geq 10$ years, hypoxemia, obesity, and one or more underlying medical conditions (Bellino et al., 2020; Dong et al., 2020; Shekerdemian et al., 2020; Feldstein et al., 2021; Fernandes et al., 2021; Ouldali et al., 2021). 


\section{PATHOPHYSIOLOGIC INSIGHTS OF CIGARETTE SMOKE- AND SARS-CoV-2- INDUCED LUNG INFLAMMATION}

As we learn more about the effects of SARS-CoV-2 in children, the question arises whether and how cigarette smoke and SARS-CoV-2 represent a new intertwined threat for children with underlying lung disease. There is concern about the possible "second hit" effect of COVID-19 on developing lungs that are already chronically impacted by environmental factors and/or prematurity and its consequences. Understanding the pathophysiologic mechanisms of CSE and SARS-CoV-2 induced inflammation and lung injury demonstrates potential areas of overlap or synergism that may lead to long-term pulmonary consequences in vulnerable pediatric populations. In this section, we review some of those mechanisms and their impact on pulmonary inflammation and injury, as summarized in Figure 1.

\section{Cigarette Smoke and Vaping}

Tobacco smoke contains more than 7,000 chemicals, including hundreds that are toxic and about 70 that can cause cancer. Tobacco burning releases a complex mixture of chemicals, both in gaseous and particulate form, that have cytotoxic and mutagenic properties, along with antigenic capacities that contribute to chronic inflammation (Lee et al., 2012). Oxidative imbalance and stress caused by CSE are responsible for direct genetic or epigenetic effects that lead to altered barrier function of the epithelial layer, epithelial to mesenchymal transition (EMT), and immune dysfunction.

Due to their anatomic location, the epithelial layers of the oral cavity and airways act as the first barrier to cigarette smoke's effects and are the cornerstone of cigarette smokeinduced inflammatory response. In regard to epithelial barrier function, cigarette smoke impairs mucociliary clearance by reducing ciliary beating and enhancing mucus production. Moreover, cigarette smoke derivatives disrupt epithelial cellular junctions, allowing for a deeper penetration of toxins and infectious agents (Aghapour et al., 2018).

Epithelial to mesenchymal transition is associated with redox imbalance and oxidative stress (Milara et al., 2013; Gohy et al., 2015) and represents an important consequence of cigarette smoke effects. EMT of airway epithelium promotes airway wall thickening and remodeling, thereby leading to airway obstruction (Eurlings et al., 2014). Alveolar EMT, rather, impacts re-epithelization (Eurlings et al., 2014; Shen et al., 2014) and contributes to the development of emphysema (Aghapour et al., 2018). EMT leads to increased fibroblast migratory capacity, invasiveness, resistance to apoptosis, and greatly increased production of extracellular matrix (ECM) components (Kalluri and Neilson, 2003).

Another important consequence of cigarette smoking is immune dysfunction. Epithelial and innate immune cells are highly responsive to cigarette derivates. Oxidative stress triggers the activation of transcription factors involved in inflammatory

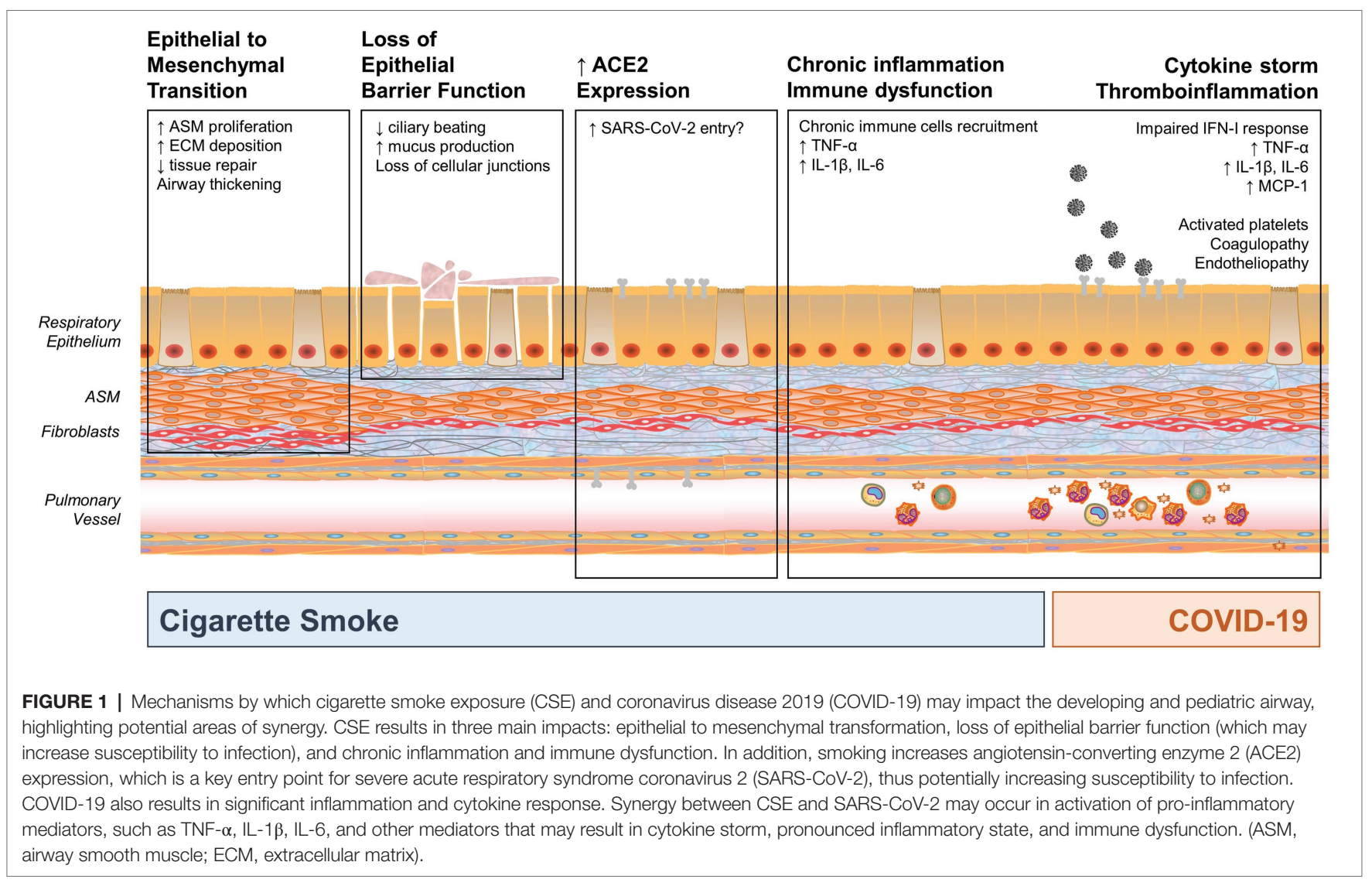


responses, such as NF-kB and AP-1. Under the activation of these transcription factors, CSE promotes a huge production of proinflammatory mediators (e.g., IL- $1 \beta$, IL- 6, TNF- $\alpha$, and granulocyte/monocyte CSF) and chemokines that are responsible for sustained immune cell recruitment and activation (Lee et al., 2012). This hyperinflammatory environment contributes to enhanced reactivity to inhaled antigens, tissue damage, and remodeling. Of note, despite being hyperactivated, innate and adaptive immune responses are highly dysfunctional in this setting (Lee et al., 2012). AP-1 activation has been related to corticosteroid resistant inflammation (Walters et al., 2005). Constitutively activated inflammation pathways are associated with reduced response to acute infectious challenges. Similarly, immune responses to viral antigens are significantly reduced, as cigarette smoke downregulates Toll-like receptor (TLR) 3-mediated responses to double-stranded RNA (Todt et al., 2013). Cigarette smoke-induced oxidative stress impairs the phagocytic activity of alveolar macrophages leading to accumulation of cellular debris and the initiation of necrotic processes. In regard to $\mathrm{T}$-cells adaptive immune responses, cigarette smoke suppresses $\mathrm{T}$ helper (Th) 1 activation and enhances Th2 and Th17 inflammation that have been associated with eosinophilic inflammation, epithelial dysfunction, and virus-induced exacerbations in COPD patients (Papi et al., 2006).

Furthermore, CSE directly influences airway smooth muscle (ASM) function, enhancing proliferation, ECM deposition, and mitochondrial dysfunction (Aravamudan et al., 2014, 2017; Vogel et al., 2014).

The pathophysiology associated with EVALI is only beginning to emerge, but among the clinical manifestations are inflammation, wet cough, phlegm, and mucociliary dysfunction (Hedman et al., 2018; Chung et al., 2019). Data suggest that e-cigarette users produce significantly more sputum than smokers and show increased markers of inflammation in their airways. As airway inflammation and mucus hypersecretion are central features underlying asthma pathology, asthmatics might be at increased risk for e-cigarette-induced health effects (Kim et al., 2017).

\section{SARS-CoV-2 Infection}

Severe acute respiratory syndrome coronavirus 2 infection starts with the viral spike protein (S-protein) binding to angiotensinconverting enzyme 2 (ACE2) receptors on the cell surface (Walls et al., 2020). ACE2 is largely expressed in epithelial cells of the respiratory tract, vascular endothelial cells, and alveolar monocytes and macrophages (Lu et al., 2020). For SARS-CoV-2 to enter cells, the S-protein must be cleaved at two different sites by host cell proteases Furin and transmembrane serine protease 2 (TMPRSS2). This process promotes cell membrane fusion and internalization of the virus. Throughout the whole process of virus contact, internalization, and replication, infected host cells are provided with a series of pattern recognition receptors (PRRs) that recognize pathogen-associated molecular patterns (PAMPs) and allow the antiviral response to start. SARS-CoV-2's lipids, proteins, genetic materials, together with intracellular calcium homeostasis alterations, are recognized by PRR as TLRs 3, 4, 7, 8, and 9, RIG-I, and MDA-5. Viral recognition leads to activation of various inflammatory pathways as NLRP3 inflammasome that induces proinflammatory cytokine release, caspase activation, and cell death; MAPK pathway leads to IL- $1 \beta / 2 / 6 / 10 / 18$, and TNF $\alpha$; secretion of interferon (IFN) $-\alpha / \beta$ (Kumar et al., 2021). INFs are key players in anti-viral host responses through inhibition of virus replication and immune activation. Interestingly, SARS-CoV-2 can inhibit an early type I IFN response in infected cells (Arunachalam et al., 2020; Miorin et al., 2020). This suppressed IFN-I production allows higher viral replication and tissue damage, further enhancing lung inflammation (Brodin, 2021). Bronchial epithelial cells, type I and II alveolar epithelial cells, and capillary endothelial cells are the site of primary infection leading to immune cell recruitment into the alveolar space and cytokine release. Many cases of severe COVID-19 are characterized by fever, elevated acute phase response markers, coagulopathy, and hemophagocytosis, suggesting a role for lung-derived cytokine storm in the pathogenesis of acute respiratory distress syndrome (ARDS), immunothrombosis, and multi-organ dysfunction (Fajgenbaum and June, 2020; Mcgonagle et al., 2021). Recent data demonstrate the persistence of anti-spike $\operatorname{Ig} G$ neutralizing antibodies up to several months after the initial infection in $>90 \%$ of infected individuals (Gudbjartsson et al., 2020; Wajnberg et al., 2020).

The significant variability in the clinical course of SARS-CoV-2 infections - ranging from asymptomatic infection, cold-like symptoms, to severe ARDS and multi-organ failure - has prompted the scientific community to identify determinants of disease severity. Male sex, age, and pre-existing conditions, such as hypertension, diabetes, and obesity are poor prognostic factors in COVID-19 (Sanyaolu et al., 2020). Impaired type I IFN responses, $\mathrm{T}_{\mathrm{H}} 1>\mathrm{T}_{\mathrm{H}} 2$ cell response, high neutrophilto-lymphocyte ratio, pre-existing inflammatory states associated with aging, and chronic diseases have been described as associated with worse outcomes (Del Valle et al., 2020; Brodin, 2021).

Focusing on children, lower ACE2 gene expression has been reported in the nasal epithelium of younger children (4-9 years old) which may in part explain the lower susceptibility to SARS-CoV-2 infection in children (Molloy and Bearer, 2020). On the other hand, children may rely on a more robust innate immune response (Consiglio et al., 2020; Gruber et al., 2020; Pierce et al., 2020) that allow them to limit viral replication and experience milder infection. ${ }^{11}$ The higher number of naive T-cells in children (Kumar et al., 2018), as well as a more recent memory for other coronaviruses infections (Mateus et al., 2020) have also been implicated in the difference in infections. There are also reports describing a different antibody response in the pediatric population regardless of disease severity (Weisberg et al., 2021). Independently from MIS-C development, SARS$\mathrm{CoV}$-2-infected children produce predominantly IgG anti-S antibody, with lower titers of anti-S IgM and IgA compared to adults. Moreover, children show significantly lower anti-N IgG that may be consistent with a lower viral load (Weisberg et al., 2021). The other aspect that has puzzled the scientific community is MIS-C pathophysiology. The temporal relationship between COVID-19 and MIS-C cases suggests that it is not

${ }^{11}$ Nature News (2020) 
directly related to viral infection but rather to the development of adaptive immunity. The massive cardiovascular involvement suggests an underlying immune-mediated disease, and proposed mechanisms involve the production of autoantibodies as a result of viral mimicry of the host, T-cells recognition of viral antigens on infected cells, and immune complexes (Jiang et al., 2020).

\section{COVID-19 and Smoking}

Smoking has definitely been associated with COVID-19 progression and worse outcomes in adults (Gulsen et al., 2020; Patanavanich and Glantz, 2020; Vardavas and Nikitara, 2020; Zhao et al., 2020). COPD patients, who typically have a significant history of smoking, are at increased risk for severe COVID-19 (Zhao et al., 2020). ACE2 gene expression in airway epithelium is upregulated by tobacco smoking (Cai et al., 2020; Leung et al., 2020), possibly through the $\alpha 7$ subtype of the nicotine acetylcholine receptor (Russo et al., 2020). Because ACE2 receptors are an important entry point for COVID-19, this may represent an increased risk for viral entry and infection in smokers. Significantly, a recent in vitro study demonstrated that acute CSE induced increased infection severity in air-liquid interface cultures derived from human airway basal stem cells by impairing IFN responses and altering tissue repair (Purkayastha et al., 2020).

Cigarette smoking is associated with underlying chronic inflammation, oxidative stress, and epithelial and immune dysfunction that may also contribute to COVID-19 progression (Gulsen et al., 2020; Shastri et al., 2021). Even if not extensively tested, the same increased risk may apply to SHS and nicotine vapers.

\section{PEDIATRIC LUNG DISEASES, CIGARETTE SMOKE EXPOSURE, AND COVID-19: A POTENTIAL INTERPLAY?}

As described above, the overarching impact of cigarette smoke, e-cigarettes, and COVID-19 is a robust inflammatory pulmonary response. While cigarette smoke-induced inflammation is meant to serve as a natural/protective response, it may make children more vulnerable to illness, since the inflammatory mediators associated with CSE may result in exacerbation of inflammatory and remodeling pathways typical of chronic pediatric lung disease. This vulnerability in combination with an immature immune system - depending on the age of the child - serves as an additional insult to the patients' respiratory and general health. While the specific contribution of COVID-19 to pediatric lung disease remains to be fully elucidated, other respiratory infections have been shown to exacerbate pediatric lung disease by increasing activation of inflammatory pathways. These multiple "hits" of CSE and pulmonary infections may certainly exacerbate preexisting chronic pediatric pulmonary disease or lead to the development of pulmonary disease in at-risk children.

\section{Wheezing Disorders, Cigarette Smoke Exposure, and COVID-19}

Children with wheezing disorders represent a pediatric population at particular risk from additional "hits" such as CSE and respiratory infections. Asthma and other wheezing disorders present a heterogeneous spectrum characterized by chronic airway inflammation, airway hyperresponsiveness, and airway remodeling (Homer and Elias, 2005; Siddiqui and Martin, 2008; Bush and Menzies-Gow, 2009; Britt et al., 2013; Bonato et al., 2019). Clinically, asthma presents with respiratory symptoms, such as wheezing, shortness of breath, chest tightness, and cough, which cause variable expiratory flow limitations. These symptoms and their intensity can vary over time and may be induced by superimposed respiratory infections or environmental exposures (Deshpande and Morgan, 2016; Testa et al., 2020). Atopy, allergic diseases such as allergic rhinitis, and maternal asthma are all risk factors increasing the likelihood of airway hyperreactivity and asthma (Martinez et al., 1995; Savenije et al., 2011). In fact, even in utero smoke exposure (maternal smoking) has been shown to increase the likelihood of developing asthma in vulnerable children (Liptzin et al., 2015). SHS exposure increases the risk of developing asthma and exacerbation of asthma symptoms (Jaakkola and Jaakkola, 1997; Weiss et al., 1999; Walker et al., 2003; Jackson et al., 2014). Indeed, chronic SHS exposure is known to exacerbate asthma by contributing and/or further enhancing airway hyperresponsiveness and structural changes (Aravamudan et al., 2017). Here, it seems that structural changes due to increased ASM proliferation and increased airway contractility due to enhanced intracellular calcium response play a major role (Hartman et al., 2012; Vogel et al., 2014).

In regard to COVID-19 and pediatric wheezing disorders, a cross-sectional study (Shekerdemian et al., 2020) conducted in North-America's pediatric intensive care units (PICU) in May 2020 found that, among children with COVID-19 infections that required PICU admission, 80\% had comorbidities such as developmental delay and/or genetic anomalies, but only $4 \%$ were reported as suffering from chronic lung disease. Overall PICU mortality was reported as $<5 \%$. Interestingly, asthma is rarely reported as comorbidity in pediatric COVID-19 cases although asthma is the most common chronic respiratory disease in children. This lack of overlap between COVID-19 and asthma is particularly interesting, as respiratory infections are typically a significant source of asthma exacerbation and morbidity. A systematic review of the current literature (Castro-Rodriguez and Forno, 2020) revealed no current data on the impact of COVID-19 in children with asthma. However, given the potentially significant implications of COVID-19 in children with asthma, the CDC emphasized the positive impact mask wearing and social distancing can make in this vulnerable patient population. Right now, health communities are encouraged to study affected populations in more detail to answer questions about the impact of COVID-19 on children with asthma, asthma severity, and the potential effects of asthma medications in treatment of COVID-19 infections (Castro-Rodriguez and Forno, 2020).

\section{Prematurity, Cigarette Smoke Exposure, and COVID-19}

Infants born prematurely are a second group at particularly high risk of pulmonary morbidity and mortality due to the 
consequences of interrupting normal prenatal pulmonary development and maturation (Pramana et al., 2011; Vrijlandt et al., 2013; Been et al., 2014). The extent and form of pulmonary compromise varies greatly depending on the level of prematurity and any additional perinatal risk factors to which the infant is exposed (Britt et al., 2013). Extremely preterm infants $[<28$ weeks gestational age $(\mathrm{GA})]$ have the highest rate of pulmonary insult because they are born prior to the saccular stage of lung development, before even primitive alveoli have started to form. These infants typically present with bronchopulmonary dysplasia (BPD), characterized by alveolar simplification, dysmorphogenesis of the alveolar capillaries, ASM proliferation, and abnormal ECM deposition (Jobe, 1999). Late preterm infants (33-36 weeks GA) are much less likely to develop BPD but are at increased risk of developing reactive airway diseases such as wheezing and asthma (Martin et al., 2013; Mcevoy et al., 2013).

Due to the pulmonary compromise that attends preterm birth, these infants commonly require respiratory support in the form of supplemental oxygen, mechanical ventilation, or continuous positive airway pressure (CPAP) to prevent hypoxia and maintain adequate alveolar recruitment and ventilation. Unfortunately, these necessary therapies may result in unintentional exacerbation of the pulmonary insults of prematurity.

In light of the numerous pulmonary insults to which preterm infants are commonly exposed in the perinatal period, they are particularly susceptible to the addition of environmental insults, such as cigarette smoke and infection. CSE is a welldocumented risk factor for development of respiratory disease in the pediatric population (Carlsen and Carlsen, 2008; Vanker et al., 2017; Grant et al., 2020). From the perspective of prematurity, maternal tobacco use is clearly associated with increased risk for premature birth as well as placenta previa, placental abruption, intrauterine growth restriction, and premature rupture of membranes (Andres and Day, 2000). Preterm infants with BPD who are exposed to second-hand smoke have been found to require supplemental oxygen for longer periods of time and to be more likely to require steroid treatment as neonates (Collaco et al., 2014; Martinez et al., 2015).

The impact of COVID-19 on preterm infants is an emerging area of investigation. SARS-CoV-2 infection appears to increase risk of preterm birth and is associated with increased risk of admission to the neonatal intensive care unit (NICU; Allotey et al., 2020; Golden and Simmons, 2020; Mimouni et al., 2020; Pettirosso et al., 2020; Woodworth et al., 2020; Yang et al., 2020b). Intriguingly, one study found that mothers hospitalized with COVID-19 earlier in pregnancy (23-33 weeks GA) were less likely to delivery early than those who were infected later in pregnancy (34-36 weeks GA; Gulersen et al., 2020). In regard to prenatal vertical transmission, there have been case reports of neonates with respiratory symptoms who tested positive for SARS-CoV-2 within $24 \mathrm{~h}$ of birth, raising concern for possible vertical transmission (Rivera-Hernandez et al., 2020; Sisman et al., 2020). However, in the vast majority of cases, infants born to mothers with COVID-19 do not test positive or develop symptoms of infection, indicating that if vertical transmission does occur, it is very rare (Pettirosso et al., 2020; Woodworth et al., 2020). Indeed, one study found that postnatal transmission between SARS-CoV-2 positive mothers and infants was very low, even when breastfeeding and allowing the infants to room with their mother after birth. In a series of 120 cases, $83 \%$ of the infants roomed with their mother after birth with the majority breastfeeding. All neonates were negative for SARS-CoV-2 after birth. About $96 \%$ of these infants were retested for SARSCoV-2 at 5-7 days of life and none tested positive (Salvatore et al., 2020). In neonates, COVID-19 most often presents with fever and mild respiratory symptoms, though it may present with gastrointestinal symptoms and abdominal distension in a subset of neonates (Golden and Simmons, 2020; Karabay et al., 2020; Marin Gabriel et al., 2020; Ng et al., 2020; Smith et al., 2020). However, there have been case reports of COVID-19 presenting with severe ARDS in the neonatal population (Frauenfelder et al., 2020; Kalyanaraman et al., 2020; Trieu et al., 2020; Wardell et al., 2020).

There is no data at this time evaluating the overlapping exposures of CSE and SARS-CoV-2 in premature infants. Both secondhand cigarette smoke and respiratory infections have been previously shown to act as additional perinatal "hits" to the vulnerable preterm lung that increase the risk of development of chronic lung disease later in life. It is therefore possible that infants infected with SARS-CoV-2 early in life may sustain lasting consequences from this pulmonary insult.

\section{SUMMARY AND CONCLUSIONS}

Overall, pediatric lung diseases remain a significant source of morbidity and mortality in children. Although advances have been made in the treatment of wheezing disorders and prematurity-related lung diseases, the health care burden remains high. The pathogenesis of such chronic lung conditions is complex and multifactorial. It is now clear that environmental insults play a role increasing susceptibility to pediatric asthma and wheezing disorders and worsen pre-existing lung diseases.

Among the environmental factors that affect the developing lung, cigarette smoke is certainly one of the most prevalent despite being preventable. While the number of adult smokers and the consequent risk of SHS exposure have decreased over time, the introduction of e-cigarettes and other vaping devices has brought up new health concerns such as EVALI and increased susceptibility to subsequent traditional smoking among adolescents. The long-term effects of CSE are ascribable to chronic inflammation and immune disfunction that lead to tissue remodeling and fibrosis, infectious susceptibility, and eventually lung function decline.

Severe acute respiratory syndrome coronavirus 2 represents a new addition to the vast number of infectious diseases that may affect children, and the current "pandemic dimension" makes COVID-19 a very prevalent threat. The clinical spectrum of COVID-19 in children is wide, ranging from asymptomatic to severe respiratory compromise and multisystem inflammatory syndrome. Determinants of COVID-19 clinical syndromes 


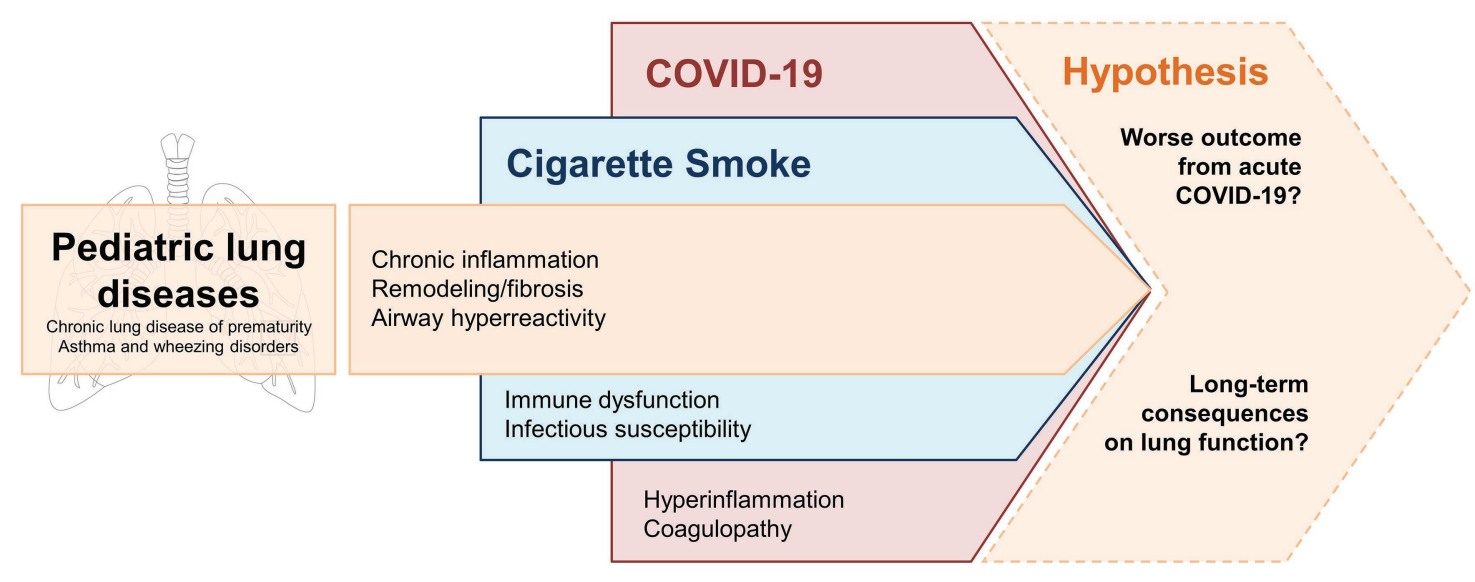

FIGURE 2 | Potential "multiple hits" effect of CSE and COVID-19 on developing lungs affected by common pediatric lung diseases - i.e., chronic lung disease of prematurity, asthma, and wheezing disorders. Underlying processes of inflammation and tissue remodeling are enhanced by chronic CSE. SARS-CoV-2 infection triggers an acute inflammatory response that may compromise the respiratory function of these vulnerable patients. Longitudinal clinical data are needed to confirm whether these factors have an additive effect that leads to more severe COVID-19 manifestations and/or long-term consequences in terms of lung function decline.

among the pediatric population are still under investigation and new contributing factors continue to emerge as we move through the pandemic. The varied manifestations suggest a role for genetic or acquired predisposition to more severe inflammatory responses. The long-term impact of SARS-CoV-2 infection on respiratory function of children with or without underlying lung diseases remains to be seen. Epidemiological data are key to identifying possible contributing factors and to guide research to better understand COVID-19 pathogenesis.

In this review, we wanted to highlight the possible detrimental interplay between the chronic inflammatory environment induced by cigarette smoke and the hyperinflammatory stimulus of COVID-19. As outlined in Figure 2, this combination has the potential to exacerbate pulmonary injury in developing lungs already affected by underlying conditions, such as chronic lung disease of prematurity, asthma, and wheezing disorders. While evidence regarding the intersection of cigarette smoke and COVID-19 pulmonary effects remain limited at this time, we agree with recommendations coming from major health associations to strongly encourage cigarette smoking cessation during the ongoing SARS-CoV-2 pandemic ${ }^{12}$ (Ahluwalia et al., 2020).

${ }^{12} \mathrm{WHO}(2020)$ and CDC (2020d)

\section{REFERENCES}

AAP (2020a). More than 1 million children in U.S. diagnosed with COVID-19. Available at: https://services.aap.org/en/news-room/news-releases/aap/2020/ more-than-1-million-children-in-u.s.-diagnosed-with-covid-19/ (Accessed January 10, 2021).

AAP (2020b). Children and COVID-19: State-level data report. Available at: https://services.aap.org/en/pages/2019-novel-coronavirus-covid-19-infections/ children-and-covid-19-state-level-data-report/ (Accessed January 10, 2021).

Aghapour, M., Raee, P., Moghaddam, S. J., Hiemstra, P. S., and Heijink, I. H. (2018). Airway epithelial barrier dysfunction in chronic obstructive pulmonary disease: role of cigarette smoke exposure. Am. J. Respir. Cell Mol. Biol. 58, 157-169. doi: $10.1165 / \mathrm{rcmb} .2017-0200 \mathrm{TR}$
Children and adolescents with pre-existing lung conditions represent an extremely vulnerable population, in particular during this unprecedented time of reduced access to healthcare resources, stay-at-home mandates that may increase the risk of SHS exposure from household members, and social isolation that may encourage addictive behaviors such as vaping in young people.

\section{AUTHOR CONTRIBUTIONS}

All authors contributed to the manuscript equally and were involved throughout the entire process.

\section{FUNDING}

This review was supported by the Department of Anesthesiology \& Perioperative Medicine, Mayo Clinic, Rochester, MN, R01 grants HL138402 and HL142061 (CMP), and CCaTS-CBD Pilot Award for Team Science from Mayo Clinic (ERV).

Ahluwalia, I. B., Myers, M., and Cohen, J. E. (2020). COVID-19 pandemic: an opportunity for tobacco use cessation. Lancet Public Health 5:e577. doi: $10.1016 / \mathrm{S} 2468-2667(20) 30236-\mathrm{X}$

Akinbami, L. J., Kit, B. K., and Simon, A. E. (2013). Impact of environmental tobacco smoke on children with asthma, United States, 2003-2010. Acad. Pediatr. 13, 508-516. doi: 10.1016/j.acap.2013.07.003

Allotey, J., Stallings, E., Bonet, M., Yap, M., Chatterjee, S., Kew, T., et al. (2020). Clinical manifestations, risk factors, and maternal and perinatal outcomes of coronavirus disease 2019 in pregnancy: living systematic review and meta-analysis. BMJ 370:m3320. doi: 10.1136/bmj. m3320

Anderson, K. R., Villafranco, N., Hatzenbuehler Cameron, L., Schallert, E. K., Joshi-Patel, A., Arrington, A., et al. (2021). A 16-year-old boy with cough 
and fever in the era of COVID-19. Pediatrics 147:e2020008235. doi: 10.1542/ peds.2020-008235

Andres, R. L., and Day, M. C. (2000). Perinatal complications associated with maternal tobacco use. Semin. Neonatol. 5, 231-241. doi: 10.1053/siny.2000.0025

Aravamudan, B., Kiel, A., Freeman, M., Delmotte, P., Thompson, M., Vassallo, R., et al. (2014). Cigarette smoke-induced mitochondrial fragmentation and dysfunction in human airway smooth muscle. Am. J. Phys. Lung Cell. Mol. Phys. 306, L840-L854. doi: 10.1152/ajplung.00155.2013

Aravamudan, B., Thompson, M., Sieck, G. C., Vassallo, R., Pabelick, C. M., and Prakash, Y. S. (2017). Functional effects of cigarette smoke-induced changes in airway smooth muscle mitochondrial morphology. J. Cell. Physiol. 232, 1053-1068. doi: $10.1002 /$ jcp. 25508

Arunachalam, P. S., Wimmers, F., Mok, C. K. P., Perera, R., Scott, M., Hagan, T., et al. (2020). Systems biological assessment of immunity to mild versus severe COVID-19 infection in humans. Science 369, 1210-1220. doi: 10.1126/ science.abc6261

Been, J. V., Lugtenberg, M. J., Smets, E., van Schayck, C. P., Kramer, B. W., Mommers, M., et al. (2014). Preterm birth and childhood wheezing disorders: a systematic review and meta-analysis. PLoS Med. 11:e1001596. doi: 10.1371/ journal.pmed.1001596

Bellino, S., Punzo, O., Rota, M. C., Del Manso, M., Urdiales, A. M., Andrianou, X., et al. (2020). COVID-19 disease severity risk factors for pediatric patients in Italy. Pediatrics 146:e2020009399. doi: 10.1542/peds.2020-009399

Best, D.Committee on Environmental HealthCommittee on Native American Child HealthCommittee on Adolescence (2009). From the American academy of pediatrics: technical report--secondhand and prenatal tobacco smoke exposure. Pediatrics 124, e1017-e1044. doi: 10.1542/peds.2009-2120

Boehmer, T. K., Devies, J., Caruso, E., van Santen, K. L., Tang, S., Black, C. L., et al. (2020). Changing age distribution of the COVID-19 pandemic-United States, May-august 2020. MMWR Morb. Mortal. Wkly Rep. 69, 1404-1409. doi: $10.15585 / \mathrm{mmwr} . \mathrm{mm} 6939 \mathrm{e} 1$

Bonato, M., Tine, M., Bazzan, E., Biondini, D., Saetta, M., and Baraldo, S. (2019). Early airway pathological changes in children: new insights into the natural history of wheezing. J. Clin. Med. 8:1180. doi: 10.3390/jcm8081180

Britt, R. D. Jr., Faksh, A., Vogel, E., Martin, R. J., Pabelick, C. M., and Prakash, Y. S. (2013). Perinatal factors in neonatal and pediatric lung diseases. Expert Rev. Respir. Med. 7, 515-531. doi: 10.1586/17476348.2013.838020

Brodin, P. (2021). Immune determinants of COVID-19 disease presentation and severity. Nat. Med. 27, 28-33. doi: 10.1038/s41591-020-01202-8

Burke, H., Leonardi-Bee, J., Hashim, A., Pine-Abata, H., Chen, Y., Cook, D. G., et al. (2012). Prenatal and passive smoke exposure and incidence of asthma and wheeze: systematic review and meta-analysis. Pediatrics 129, 735-744. doi: $10.1542 /$ peds.2011-2196

Bush, A., and Menzies-Gow, A. (2009). Phenotypic differences between pediatric and adult asthma. Proc. Am. Thorac. Soc. 6, 712-719. doi: 10.1513/ pats.200906-046DP

Cai, G., Bosse, Y., Xiao, F., Kheradmand, F., and Amos, C. I. (2020). Tobacco smoking increases the lung gene expression of ACE2, the receptor of SARSCoV-2. Am. J. Respir. Crit. Care Med. 201, 1557-1559. doi: 10.1164/ rccm.202003-0693LE

Carlsen, K. H., and Carlsen, K. C. (2008). Respiratory effects of tobacco smoking on infants and young children. Paediatr. Respir. Rev. 9, 11-19. doi: 10.1016/j. prrv.2007.11.007

Carroll Chapman, S. L., and Wu, L. T. (2014). E-cigarette prevalence and correlates of use among adolescents versus adults: a review and comparison. J. Psychiatr. Res. 54, 43-54. doi: 10.1016/j.jpsychires.2014.03.005

Castro-Rodriguez, J. A., and Forno, E. (2020). Asthma and COVID-19 in children: a systematic review and call for data. Pediatr. Pulmonol. 55, 2412-2418. doi: 10.1002/ppul.24909

CDC (2020a). Asthma. Available at: https://www.cdc.gov/nchs/fastats/asthma. htm (Accessed January 10, 2021).

CDC (2020b). Infections among children. Available at: https://www.cdc.gov/ coronavirus/2019-ncov/hcp/pediatric-hcp.html (Accessed January 10, 2021).

CDC (2020c). Multisystem inflammatory syndrome in children (MIS-C) associated with coronavirus disease 2019 (COVID-19). Available at: https://emergency. cdc.gov/han/2020/han00432.asp (Accessed January 10, 2021).

CDC (2020d). People with certain medical conditions. Smoking. Available at: https://www.cdc.gov/coronavirus/2019-ncov/need-extra-precautions/peoplewith-medical-conditions.html\#smoking (Accessed March 10, 2021).
Center for Disease Prevention and Control (2020). Outbreak of lung injury associated with the use of e-cigarette, or vaping, products. Available at: https://www.cdc.gov/tobacco/basic_information/e-cigarettes/severe-lungdisease.html (Accessed March 10, 2021).

Centers for Disease Control and Prevention (2013). Notes from the field: electronic cigarette use among middle and high school students-United States, 2011-2012. MMWR Morb. Mortal. Wkly Rep. 62, 729-730.

Chang, T. H., Wu, J. L., and Chang, L. Y. (2020). Clinical characteristics and diagnostic challenges of pediatric COVID-19: a systematic review and metaanalysis. J. Formos. Med. Assoc. 119, 982-989. doi: 10.1016/j.jfma.2020.04.007

Choi, K., and Bernat, D. (2016). E-cigarette use among Florida youth with and without asthma. Am. J. Prev. Med. 51, 446-453. doi: 10.1016/j. amepre.2016.03.010

Chung, S., Baumlin, N., Dennis, J. S., Moore, R., Salathe, S. F., Whitney, P. L., et al. (2019). Electronic cigarette vapor with nicotine causes airway mucociliary dysfunction preferentially via TRPA1 receptors. Am. J. Respir. Crit. Care Med. 200, 1134-1145. doi: 10.1164/rccm.201811-2087OC

Collaco, J. M., Aherrera, A. D., Ryan, T., and Mcgrath-Morrow, S. A. (2014). Secondhand smoke exposure in preterm infants with bronchopulmonary dysplasia. Pediatr. Pulmonol. 49, 173-178. doi: 10.1002/ppul.22819

Consiglio, C. R., Cotugno, N., Sardh, F., Pou, C., Amodio, D., Rodriguez, L., et al. (2020). The immunology of multisystem inflammatory syndrome in children with COVID-19. Cell 183, 968-981.e7. doi: 10.1016/j.cell.2020.09.016

Darmawan, D. O., Gwal, K., Goudy, B. D., Jhawar, S., and Nandalike, K. (2020). Vaping in today's pandemic: E-cigarette, or vaping, product useassociated lung injury mimicking COVID-19 in teenagers presenting with respiratory distress. SAGE Open Med. Case Rep. 8:2050313X20969590. doi: $10.1177 / 2050313$ X20969590

Das, S. K. (2003). Harmful health effects of cigarette smoking. Mol. Cell. Biochem. 253, 159-165. doi: 10.1023/A:1026024829294

Davies, N. G., Klepac, P., Liu, Y., Prem, K., Jit, M., CMMID COVID-19 working groupet al. (2020). Age-dependent effects in the transmission and control of COVID-19 epidemics. Nat. Med. 26, 1205-1211. doi: 10.1038/ s41591-020-0962-9

Del Valle, D. M., Kim-Schulze, S., Huang, H. H., Beckmann, N. D., Nirenberg, S., Wang, B., et al. (2020). An inflammatory cytokine signature predicts COVID-19 severity and survival. Nat. Med. 26, 1636-1643. doi: 10.1038/s41591-020-1051-9

Deshpande, D., and Morgan, W. (2016). Wheezing disorders in children: are girls and boys different? J. Allergy Clin. Immunol. 138, 1569-1570. doi: 10.1016/j.jaci.2016.07.034

Dong, Y., Mo, X., Hu, Y., Qi, X., Jiang, F., Jiang, Z., et al. (2020). Epidemiology of COVID-19 among children in China. Pediatrics 145:e20200702. doi: 10.1542/peds.2020-0702

Eurlings, I. M., Reynaert, N. L., van Den Beucken, T., Gosker, H. R., de Theije, C. C., Verhamme, F. M., et al. (2014). Cigarette smoke extract induces a phenotypic shift in epithelial cells; involvement of HIFlalpha in mesenchymal transition. PLoS One 9:e107757. doi: 10.1371/journal.pone.0107757

European Center for Disease Prevention and Control (2020). Rapid risk assessment: coronavirus disease 2019 (COVID-19) in the EU/EEA and the UK - eleventh update: resurgence of cases. Available at: https://www.ecdc.europa.eu/en/ publications-data/rapid-risk-assessment-coronavirus-disease-2019-covid-19eueea-and-uk-eleventh (Accessed January 10, 2021).

European Center for Disease Prevention and Control (2021). Data on the 14-day age specific notification rate of the new COVID-19 cases. Available at: https://www.ecdc.europa.eu/en/publications-data/covid-19-data-14-day-agenotification-rate-new-cases (Accessed January 11, 2021).

Fajgenbaum, D. C., and June, C. H. (2020). Cytokine storm. N. Engl. J. Med. 383, 2255-2273. doi: 10.1056/NEJMra2026131

Fedele, D. A., Barnett, T. E., Dekevich, D., Gibson-Young, L. M., Martinasek, M., and Jagger, M. A. (2016). Prevalence of and beliefs about electronic cigarettes and hookah among high school students with asthma. Ann. Epidemiol. 26, 865-869. doi: 10.1016/j.annepidem.2016.10.004

Feldstein, L. R., Tenforde, M. W., Friedman, K. G., Newhams, M., Rose, E. B., Dapul, H., et al. (2021). Characteristics and outcomes of US children and adolescents with multisystem inflammatory syndrome in children (MIS-C) compared with severe acute COVID-19. JAMA 325, 1074-1087. doi: 10.1001/ jama.2021.2091

Fernandes, D. M., Oliveira, C. R., Guerguis, S., Eisenberg, R., Choi, J., Kim, M., et al. (2021). Severe acute respiratory syndrome coronavirus 2 clinical 
syndromes and predictors of disease severity in hospitalized children and youth. J. Pediatr. 230, 23-31 e10. doi: 10.1016/j.jpeds.2020.11.016

Frauenfelder, C., Brierley, J., Whittaker, E., Perucca, G., and Bamford, A. (2020). Infant with SARS-CoV-2 infection causing severe lung disease treated with Remdesivir. Pediatrics 146:e20201701. doi: 10.1542/peds.2020-1701

GBD 2017 Risk Factor Collaborators (2018). Global, regional, and national comparative risk assessment of 84 behavioural, environmental and occupational, and metabolic risks or clusters of risks for 195 countries and territories, 1990-2017: a systematic analysis for the global burden of disease study 2017. Lancet 392, 1923-1994. doi: 10.1016/S0140-6736(18)32225-6

Gergen, P. J., Fowler, J. A., Maurer, K. R., Davis, W. W., and Overpeck, M. D. (1998). The burden of environmental tobacco smoke exposure on the respiratory health of children 2 months through 5 years of age in the United States: third National Health and nutrition examination survey, 1988 to 1994. Pediatrics 101:E8. doi: 10.1542/peds.101.2.e8

Gohy, S. T., Hupin, C., Fregimilicka, C., Detry, B. R., Bouzin, C., Gaide Chevronay, H., et al. (2015). Imprinting of the COPD airway epithelium for dedifferentiation and mesenchymal transition. Eur. Respir. J. 45, 1258-1272. doi: 10.1183/09031936.00135814

Goksor, E., Amark, M., Alm, B., Gustafsson, P. M., and Wennergren, G. (2007). The impact of pre- and post-natal smoke exposure on future asthma and bronchial hyper-responsiveness. Acta Paediatr. 96, 1030-1035. doi: 10.1111/j. 1651-2227.2007.00296.x

Golden, T. N., and Simmons, R. A. (2020). Maternal and neonatal response to COVID-19. Am. J. Physiol. Endocrinol. Metab. 319, E315-E319. doi: 10.1152/ajpendo.00287.2020

Gotzinger, F., Santiago-Garcia, B., Noguera-Julian, A., Lanaspa, M., Lancella, L., Calo Carducci, F. I., et al. (2020). COVID-19 in children and adolescents in Europe: a multinational, multicentre cohort study. Lancet Child Adolesc. Health 4, 653-661. doi: 10.1016/S2352-4642(20)30177-2

Grant, T., Brigham, E. P., and Mccormack, M. C. (2020). Childhood origins of adult lung disease as opportunities for prevention. J Allergy Clin Immunol Pract 8, 849-858. doi: 10.1016/j.jaip.2020.01.015

Gruber, C. N., Patel, R. S., Trachtman, R., Lepow, L., Amanat, F., Krammer, F., et al. (2020). Mapping systemic inflammation and antibody responses in multisystem inflammatory syndrome in children (MIS-C). Cell 183, 982-995.e14. doi: 10.1016/j.cell.2020.09.034

Gudbjartsson, D. F., Norddahl, G. L., Melsted, P., Gunnarsdottir, K., Holm, H., Eythorsson, E., et al. (2020). Humoral immune response to SARS-CoV-2 in Iceland. N. Engl. J. Med. 383, 1724-1734. doi: 10.1056/NEJMoa2026116

Gulersen, M., Blitz, M. J., Rochelson, B., Nimaroff, M., Shan, W., and Bornstein, E. (2020). Clinical implications of SARS-CoV-2 infection in the viable preterm period. Am. J. Perinatol. 37, 1077-1083. doi: 10.1055/s-0040-1713851

Gulsen, A., Yigitbas, B. A., Uslu, B., Dromann, D., and Kilinc, O. (2020). The effect of smoking on COVID-19 symptom severity: systematic review and meta-analysis. Pulm. Med. 2020:7590207. doi: 10.1155/2020/7590207

Hartman, W. R., Smelter, D. F., Sathish, V., Karass, M., Kim, S., Aravamudan, B., et al. (2012). Oxygen dose responsiveness of human fetal airway smooth muscle cells. Am. J. Phys. Lung Cell. Mol. Phys. 303, L711-L719. doi: 10.1152/ ajplung.00037.2012

Hassoun, A., Brady, K., Arefi, R., Trifonova, I., and Tsirilakis, K. (2020). Vapingassociated lung injury during COVID-19 multisystem inflammatory syndrome outbreak. J. Emerg. Med. doi: 10.1016/j.jemermed.2020.12.005 [Epub ahead of print]

Hedman, L., Backman, H., Stridsman, C., Bosson, J. A., Lundback, M., Lindberg, A., et al. (2018). Association of electronic cigarette use with smoking habits, demographic factors, and respiratory symptoms. JAMA Netw. Open 1:e180789. doi: 10.1001/jamanetworkopen.2018.0789

Hollenbach, J. P., Schifano, E. D., Hammel, C., and Cloutier, M. M. (2017). Exposure to secondhand smoke and asthma severity among children in Connecticut. PLoS One 12:e0174541. doi: 10.1371/journal.pone.0174541

Homer, R. J., and Elias, J. A. (2005). Airway remodeling in asthma: therapeutic implications of mechanisms. Physiology (Bethesda) 20, 28-35. doi: 10.1152/ physiol.00035.2004

Jaakkola, M. S., and Jaakkola, J. J. (1997). Assessment of exposure to environmental tobacco smoke. Eur. Respir. J. 10, 2384-2397. doi: 10.1183/09031936.97.10102384

Jackson, D. J., Hartert, T. V., Martinez, F. D., Weiss, S. T., and Fahy, J. V. (2014). Asthma: NHLBI workshop on the primary prevention of chronic lung diseases. Ann. Am. Thorac. Soc. 11, S139-S145. doi: 10.1513/AnnalsATS.201312-448LD
Jiang, L., Tang, K., Levin, M., Irfan, O., Morris, S. K., Wilson, K., et al. (2020). COVID-19 and multisystem inflammatory syndrome in children and adolescents. Lancet Infect. Dis. 20, e276-e288. doi: 10.1016/S1473-3099(20)30651-4

Jobe, A. J. (1999). The new BPD: an arrest of lung development. Pediatr. Res. 46, 641-643. doi: 10.1203/00006450-199912000-00007

Jones, L. L., Hashim, A., Mckeever, T., Cook, D. G., Britton, J., and Leonardi-Bee, J. (2011). Parental and household smoking and the increased risk of bronchitis, bronchiolitis and other lower respiratory infections in infancy: systematic review and meta-analysis. Respir. Res. 12:5. doi: 10.1186/1465-9921-12-5

Kalluri, R., and Neilson, E. G. (2003). Epithelial-mesenchymal transition and its implications for fibrosis. J. Clin. Invest. 112, 1776-1784. doi: 10.1172/ JCI200320530

Kalyanaraman, M., Mcqueen, D., Morparia, K., and Bergel, M. (2020). ARDS in an ex-premature infant with bronchopulmonary dysplasia and COVID-19. Pediatr. Pulmonol. 55, 2506-2507. doi: 10.1002/ppul.24989

Karabay, M., Cinar, N., Karakaya Suzan, O., Yalnizoglu Caka, S., and Karabay, O. (2020). Clinical characteristics of confirmed COVID-19 in newborns: a systematic review. J. Matern. Fetal Neonatal Med. doi: 10.1080/ 14767058.2020.1849124 [Epub ahead of print]

Kim, S. Y., Sim, S., and Choi, H. G. (2017). Active, passive, and electronic cigarette smoking is associated with asthma in adolescents. Sci. Rep. 7:17789. doi: 10.1038/s41598-017-17958-y

Kumar, B. V., Connors, T. J., and Farber, D. L. (2018). Human T cell development, localization, and function throughout life. Immunity 48, 202-213. doi: 10.1016/j.immuni.2018.01.007

Kumar, P., Sobhanan, J., Takano, Y., and Biju, V. (2021). Molecular recognition in the infection, replication, and transmission of COVID-19-causing SARSCoV-2: an emerging interface of infectious disease, biological chemistry, and nanoscience. NPG Asia Mater. 13:14. doi: 10.1038/s41427-020-00275-8

Larsen, K., Faulkner, G. E. J., Boak, A., Hamilton, H. A., Mann, R. E., Irving, H. M., et al. (2016). Looking beyond cigarettes: are Ontario adolescents with asthma less likely to smoke e-cigarettes, marijuana, waterpipes or tobacco cigarettes? Respir. Med. 120, 10-15. doi: 10.1016/j.rmed.2016.09.013

Layden, J. E., Ghinai, I., Pray, I., Kimball, A., Layer, M., Tenforde, M. W., et al. (2020). Pulmonary illness related to E-cigarette use in Illinois and Wisconsin-final report. N. Engl. J. Med. 382, 903-916. doi: 10.1056/ NEJMoa1911614

Lee, J., Taneja, V., and Vassallo, R. (2012). Cigarette smoking and inflammation: cellular and molecular mechanisms. J. Dent. Res. 91, 142-149. doi: $10.1177 / 0022034511421200$

Leung, J. M., Yang, C. X., Tam, A., Shaipanich, T., Hackett, T. L., Singhera, G. K., et al. (2020). ACE-2 expression in the small airway epithelia of smokers and COPD patients: implications for COVID-19. Eur. Respir. J. 55:2000688 doi: $10.1183 / 13993003.00688-2020$

Liptzin, D. R., Landau, L. I., and Taussig, L. M. (2015). Sex and the lung: observations, hypotheses, and future directions. Pediatr. Pulmonol. 50, 1159-1169. doi: 10.1002/ppul.23178

Liu, Y., Yan, L. M., Wan, L., Xiang, T. X., Le, A., Liu, J. M., et al. (2020). Viral dynamics in mild and severe cases of COVID-19. Lancet Infect. Dis. 20, 656-657. doi: 10.1016/S1473-3099(20)30232-2

Lu, R., Zhao, X., Li, J., Niu, P., Yang, B., Wu, H., et al. (2020). Genomic characterisation and epidemiology of 2019 novel coronavirus: implications for virus origins and receptor binding. Lancet 395, 565-574. doi: 10.1016/ S0140-6736(20)30251-8

Marin Gabriel, M. A., Reyne Vergeli, M., Caserio Carbonero, S., Sole, L., Carrizosa Molina, T., Rivero Calle, I., et al. (2020). Maternal, perinatal and neonatal outcomes with COVID-19: a multicenter study of 242 pregnancies and their 248 infant newborns during their first month of life. Pediatr. Infect. Dis. J. 39, e393-e397. doi: 10.1097/INF.0000000000002902

Martin, R. J., Prakash, Y. S., and Hibbs, A. M. (2013). Why do former preterm infants wheeze? J. Pediatr. 162, 443-444. doi: 10.1016/j.jpeds.2012.11.028

Martinasek, M. P., White, R. M., Wheldon, C. W., and Gibson-Young, L. (2019). Perceptions of non-traditional tobacco products between asthmatic and nonasthmatic college students. J. Asthma 56, 498-504. doi: 10.1080/02770903.2018.1471705

Martinez, S., Garcia-Meric, P., Millet, V., Aymeric-Ponsonnet, M., Alagha, K., and Dubus, J. C. (2015). Tobacco smoke in infants with bronchopulmonary dysplasia. Eur. J. Pediatr. 174, 943-948. doi: 10.1007/s00431-015-2491-y

Martinez, F. D., Wright, A. L., Taussig, L. M., Holberg, C. J., Halonen, M., and Morgan, W. J. (1995). Asthma and wheezing in the first six years of 
life. The group health medical associates. N. Engl. J. Med. 332, 133-138. doi: 10.1056/NEJM199501193320301

Mateus, J., Grifoni, A., Tarke, A., Sidney, J., Ramirez, S. I., Dan, J. M., et al. (2020). Selective and cross-reactive SARS-CoV-2 T cell epitopes in unexposed humans. Science 370, 89-94. doi: 10.1126/science.abd3871

Mcevoy, C., Venigalla, S., Schilling, D., Clay, N., Spitale, P., and Nguyen, T. (2013). Respiratory function in healthy late preterm infants delivered at 33-36 weeks of gestation. J. Pediatr. 162, 464-469. doi: 10.1016/j.jpeds.2012.09.042

Mcgonagle, D., Ramanan, A. V., and Bridgewood, C. (2021). Immune cartography of macrophage activation syndrome in the COVID-19 era. Nat. Rev. Rheumatol. 17, 145-157. doi: 10.1038/s41584-020-00571-1

Miech, R., Johnston, L., O'malley, P. M., Bachman, J. G., and Patrick, M. E. (2019). Trends in adolescent vaping, 2017-2019. N. Engl. J. Med. 381, 1490-1491. doi: 10.1056/NEJMc1910739

Milara, J., Peiro, T., Serrano, A., and Cortijo, J. (2013). Epithelial to mesenchymal transition is increased in patients with COPD and induced by cigarette smoke. Thorax 68, 410-420. doi: 10.1136/thoraxjnl-2012-201761

Mimouni, F., Lakshminrusimha, S., Pearlman, S. A., Raju, T., Gallagher, P. G., and Mendlovic, J. (2020). Perinatal aspects on the covid-19 pandemic: a practical resource for perinatal-neonatal specialists. J. Perinatol. 40, 820-826. doi: 10.1038/s41372-020-0665-6

Miorin, L., Kehrer, T., Sanchez-Aparicio, M. T., Zhang, K., Cohen, P., Patel, R. S., et al. (2020). SARS-CoV-2 Orf6 hijacks Nup98 to block STAT nuclear import and antagonize interferon signaling. Proc. Natl. Acad. Sci. U. S. A. 117, 28344-28354. doi: 10.1073/pnas.2016650117

Molloy, E. J., and Bearer, C. F. (2020). COVID-19 in children and altered inflammatory responses. Pediatr. Res. 88, 340-341. doi: 10.1038/ s41390-020-0881-y

National Institute of Health (2018). Teens using vaping devices in record numbers. Available at: https://www.nih.gov/news-events/news-releases/teensusing-vaping-devices-record-numbers (Accessed January 10, 2021).

Nature News (2020). How kids' immune system can evade COVID. Available at: https://www.nature.com/articles/d41586-020-03496-7 (Accessed January 10, 2021)

Neophytou, A. M., Oh, S. S., White, M. J., Mak, A. C. Y., Hu, D., Huntsman, S., et al. (2018). Secondhand smoke exposure and asthma outcomes among African-American and Latino children with asthma. Thorax 73, 1041-1048. doi: 10.1136/thoraxjnl-2017-211383

Ng, K. F., Bandi, S., Bird, P. W., and Wei-Tze Tang, J. (2020). COVID-19 in neonates and infants: progression and recovery. Pediatr. Infect. Dis. J. 39, e140-e142. doi: 10.1097/INF.0000000000002738

NYC Health (2020). 2020 Health Alert \#13. Pediatric multi-system inflammatory syndrome potentially associated with COVID-19. Available at: https://www1. nyc.gov/assets/doh/downloads/pdf/han/alert/2020/covid-19-pediatric-multisystem-inflammatory-syndrome.pdf (Accessed March 10, 2021).

Ouldali, N., Yang, D. D., Madhi, F., Levy, M., Gaschignard, J., Craiu, I., et al. (2021). Factors associated with severe SARS-CoV-2 infection. Pediatrics 147:e2020023432. doi: 10.1542/peds.2020-023432

Papi, A., Bellettato, C. M., Braccioni, F., Romagnoli, M., Casolari, P., Caramori, G., et al. (2006). Infections and airway inflammation in chronic obstructive pulmonary disease severe exacerbations. Am. J. Respir. Crit. Care Med. 173, 1114-1121. doi: 10.1164/rccm.200506-859OC

Parri, N., Lenge, M., Cantoni, B., Arrighini, A., Romanengo, M., Urbino, A., et al. (2020). COVID-19 in 17 italian pediatric emergency departments. Pediatrics 146:e20201235. doi: 10.1542/peds.2020-1235

Patanavanich, R., and Glantz, S. A. (2020). Smoking is associated with COVID-19 progression: a meta-analysis. Nicotine Tob. Res. 22, 1653-1656. doi: 10.1093/ ntr/ntaa082

Pettirosso, E., Giles, M., Cole, S., and Rees, M. (2020). COVID-19 and pregnancy: a review of clinical characteristics, obstetric outcomes and vertical transmission. Aust. N. Z. J. Obstet. Gynaecol. 60, 640-659. doi: 10.1111/ajo.13204

Pierce, C. A., Preston-Hurlburt, P., Dai, Y., Aschner, C. B., Cheshenko, N., Galen, B., et al. (2020). Immune responses to SARS-CoV-2 infection in hospitalized pediatric and adult patients. Sci. Transl. Med. 12:eabd5487. doi: 10.1126/scitranslmed.abd5487

Pirkle, J. L., Bernert, J. T., Caudill, S. P., Sosnoff, C. S., and Pechacek, T. F. (2006). Trends in the exposure of nonsmokers in the U.S. population to secondhand smoke: 1988-2002. Environ. Health Perspect. 114, 853-858. doi: $10.1289 /$ ehp. 8850
Pramana, I. A., Latzin, P., Schlapbach, L. J., Hafen, G., Kuehni, C. E., Nelle, M., et al. (2011). Respiratory symptoms in preterm infants: burden of disease in the first year of life. Eur. J. Med. Res. 16, 223-230. doi: 10.1186/ 2047-783X-16-5-223

Purkayastha, A., Sen, C., Garcia, G. Jr., Langerman, J., Shia, D. W., Meneses, L. K., et al. (2020). Direct exposure to SARS-CoV-2 and cigarette smoke increases infection severity and alters the stem cell-derived airway repair response. Cell Stem Cell 27, 869-875.e4. doi: 10.1016/j.stem.2020.11.010

Reid, K. M., Forrest, J. R., and Porter, L. (2018). Tobacco product use among youths with and without lifetime asthma-Florida, 2016. MMWR Morb. Mortal. Wkly Rep. 67, 599-601. doi: 10.15585/mmwr.mm6721a2

Riphagen, S., Gomez, X., Gonzalez-Martinez, C., Wilkinson, N., and Theocharis, P. (2020). Hyperinflammatory shock in children during COVID-19 pandemic. Lancet 395, 1607-1608. doi: 10.1016/S0140-6736(20)31094-1

Rivera-Hernandez, P., Nair, J., Islam, S., Davidson, L., Chang, A., and Elberson, V. (2020). Coronavirus disease 2019 in a premature infant: vertical transmission and antibody response or lack thereof. AJP Rep. 10, e224-e227. doi: 10.1055/ s-0040-1715176

Russo, P., Bonassi, S., Giacconi, R., Malavolta, M., Tomino, C., and Maggi, F. (2020). COVID-19 and smoking: is nicotine the hidden link? Eur. Respir. J. 55:2001116. doi: 10.1183/13993003.01116-2020

Salvatore, C. M., Han, J. Y., Acker, K. P., Tiwari, P., Jin, J., Brandler, M., et al. (2020). Neonatal management and outcomes during the COVID-19 pandemic: an observation cohort study. Lancet Child Adolesc. Health 4, 721-727. doi: $10.1016 /$ S2352-4642(20)30235-2

Sanyaolu, A., Okorie, C., Marinkovic, A., Patidar, R., Younis, K., Desai, P., et al. (2020). Comorbidity and its impact on patients with COVID-19. SN Compr. Clin. Med. 1-8. doi: 10.1007/s42399-020-00408-8 [EpuB ahead of print]

Savenije, O. E., Granell, R., Caudri, D., Koppelman, G. H., Smit, H. A., Wijga, A., et al. (2011). Comparison of childhood wheezing phenotypes in 2 birth cohorts: ALSPAC and PIAMA. J. Allergy Clin. Immunol. 127, 1505-1512.e14. doi: $10.1016 /$ j.jaci.2011.02.002

Shastri, M. D., Shukla, S. D., Chong, W. C., Kc, R., Dua, K., Patel, R. P., et al. (2021). Smoking and COVID-19: what we know so far. Respir. Med. 176:106237. doi: $10.1016 /$ j.rmed.2020.106237

Shekerdemian, L. S., Mahmood, N. R., Wolfe, K. K., Riggs, B. J., Ross, C. E., Mckiernan, C. A., et al. (2020). Characteristics and outcomes of children with coronavirus disease 2019 (COVID-19) infection admitted to US and Canadian pediatric intensive care units. JAMA Pediatr. 174, 868-873. doi: 10.1001/jamapediatrics.2020.1948

Shen, H. J., Sun, Y. H., Zhang, S. J., Jiang, J. X., Dong, X. W., Jia, Y. L., et al. (2014). Cigarette smoke-induced alveolar epithelial-mesenchymal transition is mediated by Racl activation. Biochim. Biophys. Acta 1840, 1838-1849. doi: 10.1016/j.bbagen.2014.01.033

Siddiqui, S., and Martin, J. G. (2008). Structural aspects of airway remodeling in asthma. Curr Allergy Asthma Rep 8, 540-547. doi: 10.1007/s11882-008-0098-3

Sisman, J., Jaleel, M. A., Moreno, W., Rajaram, V., Collins, R. R. J., Savani, R. C., et al. (2020). Intrauterine transmission of SARS-COV-2 infection in a preterm infant. Pediatr. Infect. Dis. J. 39, e265-e267. doi: 10.1097/INF.0000000000002815

Smith, V., Seo, D., Warty, R., Payne, O., Salih, M., Chin, K. L., et al. (2020). Maternal and neonatal outcomes associated with COVID-19 infection: a systematic review. PLoS One 15:e0234187. doi: 10.1371/journal.pone.0234187

Tai, A., Tran, H., Roberts, M., Clarke, N., Wilson, J., and Robertson, C. F. (2014). The association between childhood asthma and adult chronic obstructive pulmonary disease. Thorax 69, 805-810. doi: 10.1136/thoraxjnl-2013-204815

Testa, D., DI Bari, M., Nunziata, M., DE Cristofaro, G., Massaro, G., Marcuccio, G., et al. (2020). Allergic rhinitis and asthma assessment of risk factors in pediatric patients: a systematic review. Int. J. Pediatr. Otorhinolaryngol. 129:109759. doi: 10.1016/j.ijporl.2019.109759

Thacher, J. D., Gehring, U., Gruzieva, O., Standl, M., Pershagen, G., Bauer, C. P., et al. (2018). Maternal smoking during pregnancy and early childhood and development of asthma and rhinoconjunctivitis-a MeDALL project. Environ. Health Perspect. 126:047005. doi: 10.1289/EHP2738

Thacher, J. D., Gruzieva, O., Pershagen, G., Neuman, A., Wickman, M., Kull, I., et al. (2014). Pre- and postnatal exposure to parental smoking and allergic disease through adolescence. Pediatrics 134, 428-434. doi: 10.1542/ peds.2014-0427

Todt, J. C., Freeman, C. M., Brown, J. P., Sonstein, J., Ames, T. M., Mccubbrey, A. L., et al. (2013). Smoking decreases the response of human lung macrophages 
to double-stranded RNA by reducing TLR3 expression. Respir. Res. 14:33. doi: 10.1186/1465-9921-14-33

Trieu, C., Poole, C., Cron, R. Q., Hallman, M., Rutledge, C., Bliton, K., et al. (2020). Severe neonatal coronavirus disease 2019 presenting as acute respiratory distress syndrome. Pediatr. Infect. Dis. J. 39, e367-e369. doi: 10.1097/ INF.0000000000002864

Turner, E., Fedele, D. A., Thompson, L., and Salloum, R. G. (2018). Patterns of electronic cigarette use in youth with asthma: results from a nationally representative sample. Ann. Allergy Asthma Immunol. 120, 220-222. doi: 10.1016/j.anai.2017.11.020

Um-Bergstrom, P., Hallberg, J., Pourbazargan, M., Berggren-Brostrom, E., Ferrara, G., Eriksson, M. J., et al. (2019). Pulmonary outcomes in adults with a history of Bronchopulmonary dysplasia differ from patients with asthma. Respir. Res. 20:102. doi: 10.1186/s12931-019-1075-1

Vanker, A., Gie, R. P., and Zar, H. J. (2017). The association between environmental tobacco smoke exposure and childhood respiratory disease: a review. Expert Rev. Respir. Med. 11, 661-673. doi: 10.1080/17476348.2017.1338949

Vardavas, C. I., and Nikitara, K. (2020). COVID-19 and smoking: a systematic review of the evidence. Tob. Induc. Dis. 18:20. doi: 10.18332/tid/119324

Verdoni, L., Mazza, A., Gervasoni, A., Martelli, L., Ruggeri, M., Ciuffreda, M., et al. (2020). An outbreak of severe Kawasaki-like disease at the Italian epicentre of the SARS-CoV-2 epidemic: an observational cohort study. Lancet 395, 1771-1778. doi: 10.1016/S0140-6736(20)31103-X

Verma, R., and Amin, R. (2020). Clinical pearls for COVID-19 in children: what do pediatricians need to know? Pediatr. Res. doi: 10.1038/ s41390-020-01123-9 [Epub ahead of print]

Vogel, E. R., Vanoosten, S. K., Holman, M. A., Hohbein, D. D., Thompson, M. A., Vassallo, R., et al. (2014). Cigarette smoke enhances proliferation and extracellular matrix deposition by human fetal airway smooth muscle. Am. J. Phys. Lung Cell. Mol. Phys. 307, L978-L986. doi: 10.1152/ajplung.00111.2014

Von Mutius, E. (2001). Paediatric origins of adult lung disease. Thorax 56, 153-157. doi: $10.1136 /$ thorax. 56.2 .153

Vrijlandt, E. J., Kerstjens, J. M., Duiverman, E. J., Bos, A. F., and Reijneveld, S. A. (2013). Moderately preterm children have more respiratory problems during their first 5 years of life than children born full term. Am. J. Respir. Crit. Care Med. 187, 1234-1240. doi: 10.1164/rccm.201211-2070OC

Wajnberg, A., Amanat, F., Firpo, A., Altman, D. R., Bailey, M. J., Mansour, M., et al. (2020). Robust neutralizing antibodies to SARS-CoV-2 infection persist for months. Science 370, 1227-1230. doi: 10.1126/science.abd7728

Walker, B. Jr., Stokes, L. D., and Warren, R. (2003). Environmental factors associated with asthma. J. Natl. Med. Assoc. 95, 152-166.

Walls, A. C., Park, Y. J., Tortorici, M. A., Wall, A., Mcguire, A. T., and Veesler, D. (2020). Structure, function, and antigenicity of the SARS-CoV-2 spike glycoprotein. Cell 181, 281-292 e286. doi: 10.1016/j.cell.2020.02.058

Walters, M. J., Paul-Clark, M. J., Mcmaster, S. K., Ito, K., Adcock, I. M., and Mitchell, J. A. (2005). Cigarette smoke activates human monocytes by an oxidant-AP-1 signaling pathway: implications for steroid resistance. Mol. Pharmacol. 68, 1343-1353. doi: 10.1124/mol.105.012591

Wang, Z., May, S. M., Charoenlap, S., Pyle, R., Ott, N. L., Mohammed, K., et al. (2015). Effects of secondhand smoke exposure on asthma morbidity and health care utilization in children: a systematic review and meta-analysis. Ann. Allergy Asthma Immunol. 115, 396-401.e2. doi: 10.1016/j.anai.2015.08.005
Wardell, H., Campbell, J. I., Vanderpluym, C., and Dixit, A. (2020). Severe acute respiratory syndrome coronavirus 2 infection in febrile neonates. J. Pediatric Infect. Dis. Soc. 9, 630-635. doi: 10.1093/jpids/piaa084

Weisberg, S. P., Connors, T. J., Zhu, Y., Baldwin, M. R., Lin, W. H., Wontakal, S., et al. (2021). Distinct antibody responses to SARS-CoV-2 in children and adults across the COVID-19 clinical spectrum. Nat. Immunol. 22, 25-31. doi: $10.1038 / \mathrm{s} 41590-020-00826-9$

Weiss, S. T., Utell, M. J., and Samet, J. M. (1999). Environmental tobacco smoke exposure and asthma in adults. Environ. Health Perspect. 107, 891-895. doi: $10.1289 /$ ehp.99107s6891

WHO (2020). Smoking and COVID-19. Available at: https://www.who.int/newsroom/commentaries/detail/smoking-and-covid-19 (Accessed March 10, 2021).

Woodworth, K. R., Olsen, E. O., Neelam, V., Lewis, E. L., Galang, R. R., Oduyebo, T., et al. (2020). Birth and infant outcomes following laboratoryconfirmed SARS-CoV-2 infection in pregnancy-SET-NET, 16 jurisdictions, march 29-October 14, 2020. MMWR Morb. Mortal. Wkly Rep. 69, 1635-1640. doi: 10.15585/mmwr.mm6944e2

Wu, Q., Xing, Y., Shi, L., Li, W., Gao, Y., Pan, S., et al. (2020). Coinfection and other clinical characteristics of COVID-19 in children. Pediatrics 146:e20200961. doi: 10.1542/peds.2020-0961

Xia, W., Shao, J., Guo, Y., Peng, X., Li, Z., and Hu, D. (2020). Clinical and CT features in pediatric patients with COVID-19 infection: different points from adults. Pediatr. Pulmonol. 55, 1169-1174. doi: 10.1002/ppul.24718

Yang, R., Mei, H., Zheng, T., Fu, Q., Zhang, Y., Buka, S., et al. (2020b). Pregnant women with COVID-19 and risk of adverse birth outcomes and maternal-fetal vertical transmission: a population-based cohort study in Wuhan, China. BMC Med. 18:330. doi: 10.1186/s12916-020-01798-1

Yang, J., Zheng, Y., Gou, X., Pu, K., Chen, Z., Guo, Q., et al. (2020a). Prevalence of comorbidities and its effects in patients infected with SARS-CoV-2: a systematic review and meta-analysis. Int. J. Infect. Dis. 94, 91-95. doi: 10.1016/j.ijid.2020.03.017

Yao, T., Sung, H. Y., Wang, Y., Lightwood, J., and Max, W. (2019). Healthcare costs of secondhand smoke exposure at home for U.S. children. Am. J. Prev. Med. 56, 281-287. doi: 10.1016/j.amepre.2018.08.013

Yoon, S., Li, H., Lee, K. H., Hong, S. H., Kim, D., Im, H., et al. (2020). Clinical characteristics of asymptomatic and symptomatic pediatric coronavirus disease 2019 (COVID-19): a systematic review. Medicina 56:474. doi: 10.3390/ medicina56090474

Zhao, Q., Meng, M., Kumar, R., Wu, Y., Huang, J., Lian, N., et al. (2020). The impact of COPD and smoking history on the severity of COVID-19: a systemic review and meta-analysis. J. Med. Virol. 92, 1915-1921. doi: 10.1002/jmv.25889

Conflict of Interest: The authors declare that the research was conducted in the absence of any commercial or financial relationships that could be construed as a potential conflict of interest.

Copyright $\odot 2021$ Schiliro, Vogel, Paolini and Pabelick. This is an open-access article distributed under the terms of the Creative Commons Attribution License (CC BY). The use, distribution or reproduction in other forums is permitted, provided the original author(s) and the copyright owner(s) are credited and that the original publication in this journal is cited, in accordance with accepted academic practice. No use, distribution or reproduction is permitted which does not comply with these terms. 